\title{
FEATURE On the ratio of wind- to water-driven sediment transport: Conserving soil under global-change-type extreme events
}

\author{
Jason P. Field, David D. Breshears, Jeffrey J. Whicker, and Chris B. Zou
}

W

ind and water are fundamental drivers of land surface dynamics through their net effects on sediment transport and associated soil erosion. In arid and semiarid environments, where vegetation cover is usually sparse, windand water-driven sediment transport can potentially occur over similar spatial and temporal scales and both can contribute substantially to total erosion (Oldeman et al. 1990; Breshears et al. 2003; Field et al. 2009). Sediment transport and associated soil erosion remains a serious and persistent environmental problem worldwide because of its potential adverse impacts on soil productivity, air and water quality, and ecosystem health (Trimble and Crosson 2000; MEA 2005). Notably, roughly twothirds of the world's arable land is affected by moderate to severe soil degradation (Pimentel et al. 1995), most of which is attributed to wind and water erosional processes (Oldeman et al. 1990). The combined impact of wind and water erosion on agricultural land translates directly into considerable financial costs (Pimentel et al. 1995), and their effects permeate across all major types of ecosystem goods and services (MEA 2005). Further, synergistic relationships between wind- and water-driven sediment transport could be particularly important in dryland ecosystems because both processes can operate on the soil surface to redistribute sediment and other ecological resources, such as nutrients, seeds, and water (Aguiar and Sala 1999; Field et al. 2011). The degree to which wind and water processes inter-

Jason P. Field is research specialist in the School of Natural Resources and the Environment at the University of Arizona, Tucson, Arizona. David D. Breshears is professor in the School of Natural Resources and the Environment and the Department of Ecology and Evolutionary Biology at the University of Arizona, Tucson, Arizona. Jeffrey J. Whicker is environmental scientist in the Environmental Programs Division at Los Alamos National Laboratory, Los Alamos, New Mexico. Chris B. Zou is assistant professor in the Department of Department of Natural Resource Ecology and Management, Oklahoma State University, Stillwater, Oklahoma. act could have important implications not only for maintaining agricultura productivity but also for maintaining ecosystem health and for adapting to projected impacts of climate change (Pimentel et al. 1995; MEA 2005). For example, at regional scales wind-driven dust emissions from drylands can suppress surface precipitation via effects on atmospheric radiative forcing and condensation nuclei (Rosenfeld et al. 2001) and can reduce the duration of mountain snow cover via effects on albedo (Painter et al. 2007) - both of which can have profound impacts on water resources for many dryland regions. In addition, the transport and deposition of dust from regional source areas, such as the Sahara in North Africa, can have important global ecological implications for terrestrial and aquatic productivity through the addition of essential elements (e.g., nitrogen, phosphorous) to nutrient-poor environments such as intercoastal waters and highly weathered tropical soils (Goudie and Middleton 2006).

Wind- and water-driven sediment transport can occur at the same location over similar time scales in response to unique weather and extreme climate events, and both can contribute substantially to overall erosion, as inferred indirectly from soil pedology (Sweet 1999), experimental field measurements (Breshears et al. 2003), and erosion modeling (Oldeman et al. 1990; Trimble and Crosson 2000). Unfortunately, wind and water erosion are almost always studied independently, and rates of aeolian and fluvial sediment transport have rarely been measured directly at the same location and over the same time scale (Field et al. 2009). Such direct comparisons of wind and water erosion have generally been precluded by challenges associated with spatial differences in that flux footprints of aeolian and fluvial processes are dynamic and unlikely to be coherent at any given point in time. However, sediment transport can be directly compared between aeolian and fluvial drivers by measuring the mass of material passing through a unit length that is perpendicu- lar to the erosional force vector (Breshears et al. 2003). Sediment transport refers to the horizontal movement of soil particles across the land surface by either wind or water and differs from erosion in that there is no defined control area for which to evaluate sediment loss per unit area. Horizontal wind-driven sediment transport is not equivalent to wind erosion (i.e., vertical dust flux), but it is related to it (Gillette 1977; Shao et al. 1996; Gillette et al. 1997; Alfaro and Gomes 2001); the specific nature of this relationship, however, varies substantially in magnitude, and has only been evaluated for a few specific conditions. Horizontal aeolian sediment transport measured this way-as the mass of material passing through a unit length that is perpendicular to the erosional force vector-could in some cases be reflective of deposition rather than erosion, but height-dependent measurements indicate a profile consistent with the occurrence of erosion (i.e., upward vertical flux) rather than deposition in the vast majority of drylands (Gillette et al. 1997; Breshears et al. 2009). Similarly, water-driven sediment transport is related to rates of water erosion (e.g., Moss and Walker 1978), with the relationship being quite variable and uncertain. Notably, however, simultaneous, colocated measurements of aeolian and fluvial sediment transport remain largely lacking.

Traditional soil management focuses primarily on erosion (Toy et al. 2002), but we suggest that transport may also be important to consider not only because it is related to erosion but also because it provides important information on the dynamics of the soil surface and its associated resources. The ratio of wind-driven sediment transport to that of water (windto-water transport ratio) can be viewed as a basic site characteristic relevant to soil conservation that has not generally been explicitly considered, largely because it is uncertain and measurements are lacking. Based on the few available studies that have measured both wind- and waterdriven sediment transport (e.g., Breshears 
et al. 2003; Field et al. 2011), we hypothesize that the wind-to-water transport ratio could potentially vary by more than four orders of magnitude due to variations among basic site characteristics such as soil texture, wet-dry climate extremes, percent slope, and wind speed (figure 1) The importance of considering windand water-driven sediment transport as interrelated environmental processes has arguably been somewhat overlooked, yet is fundamental and analogous to the way in which the carbon-to-nitrogen ratio in soils must be explicitly considered for effective land management, rather than considering carbon or nitrogen in isolation of one another. Importantly, because projected climate changes for many drylands include increasing frequency of both severe droughts and intense precipitation events (IPCC 2007), and wet versus dry conditions are expected to differentially alter wind- and water-driven sediment transport and associated erosion (figure 2), considerable uncertainty remains regarding how the ratio of the two might change under these conditions.

Here we wish to highlight the need to consider the ratio of wind- to water-driven sediment fluxes as a basic site characteristic and more specifically to consider how this ratio might change in dryland ecosystems, many of which are projected to have more extreme events: both severe droughts and intense precipitation events. To consider this issue in more detail, we draw on a targeted subset of data from recently published measures of wind- and water-driven sediment fluxes in a semiarid grassland in southern Arizona (Field et al. 2011).

Wind- and water-driven sediment transport was obtained from three study plots $(50 \times 50 \mathrm{~m}[165 \times 165 \mathrm{ft}])$ in a relatively undisturbed semiarid grassland on a sandy loam upland ecological site that occupies recently deposited Holocene alluvial fan and fan terrace surfaces with $\leq 8 \%$ slopes, sandy loam soils to about $15 \mathrm{~cm}$ (6 in) depth, and $5 \%$ to $25 \%$ gravel at the surface (McClaran et al. 2003). Herbaceous cover was approximately 60\%, with Lehmann lovegrass (Eragrostis lehmanniana) constituting the majority (>90\%) of the grass cover and approximately $10 \%$ woody plant cover primarily from Velvet mesquite (Prosopis

\section{Figure 1}

Hypothesized influences of site characteristics and physical controls on the wind-towater transport ratio developed using the limited available data (Breshears et al. 2003; Field et al. 2011).

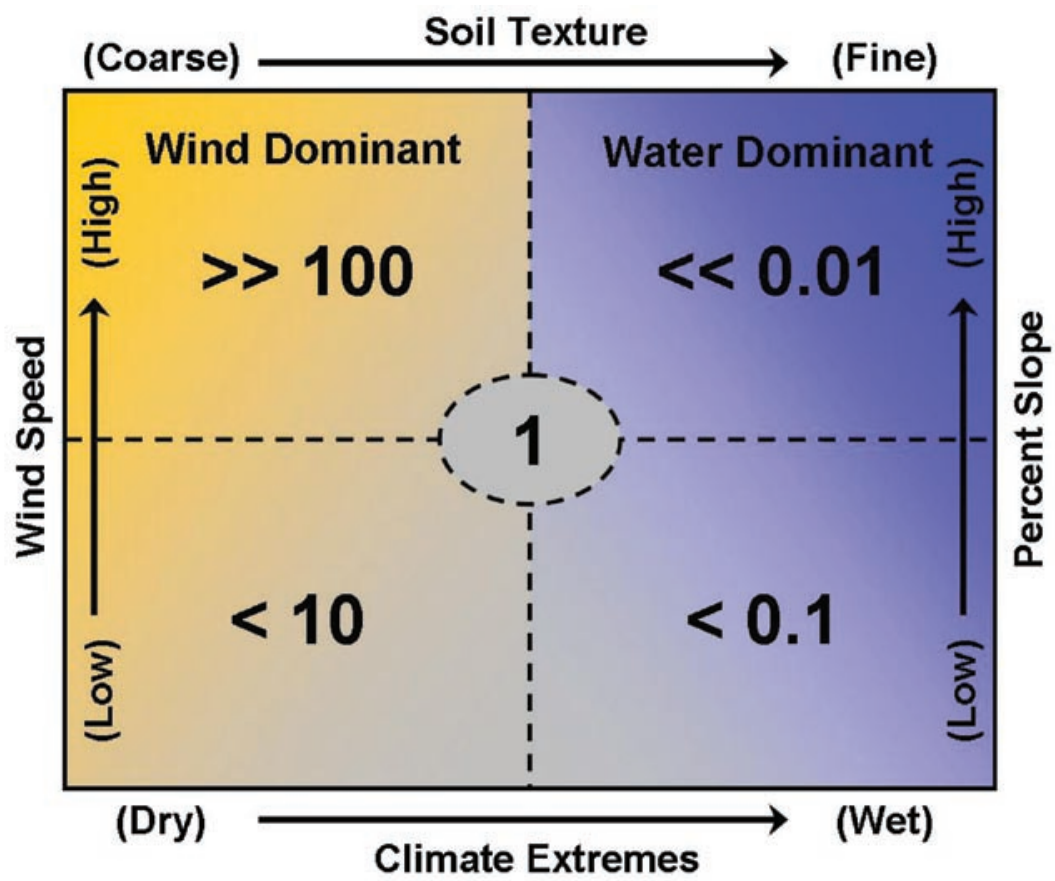

velutina). Each of the study plots were instrumented with a series of Big Spring Number Eight (BSNE) samplers at five heights aboveground $(0.08,0.17,0.25$, 0.50 , and $1.0 \mathrm{~m}[3.0,6.5,10,20$, and 39 in]) and a pair of sediment check dams (3 $\mathrm{m}[10 \mathrm{ft}]$ wide perpendicular to slope) to estimate wind- and water-driven sediment transport at the hillslope scale, respectively. Sediment was collected every 7 to 14 days. Cumulative horizontal sediment flux was calculated by integrating flux measurements from 0 to $1 \mathrm{~m}$ (0 to 39 in) above the soil surface using an exponential relationship with height (Gillette et al. 1997). The first year of this study (July 2005 to June 2006) included the unusual conditions of a 25-year precipitation event in August followed directly by the driest 9month (September to May) period on the more than 100-year instrumental record, whereas the second year (July 2006 to June 2007) served as a representative baseline year with relatively normal conditions (e.g., mean annual precipitation within 1\% of 1971 to 2000 mean).

The two one-year intervals in this study included a "baseline" year, for which annual precipitation was near nor- mal (350 $\mathrm{mm}$ [13.8 in]), and a year with wet-dry extremes. The year with wet-dry extremes served as an opportunistic ana$\log$ for a "global-change-type" year of extreme events, for which annual precipitation was about $50 \%$ below normal and included an intense 25-year precipitation event followed directly by the driest 9month period on the more than 100-year instrumental record. Under the globalchange-type conditions, annual rates of water-driven sediment transport decreased by more than $80 \%$ relative to baseline conditions (e.g., mean annual precipitation within $1 \%$ of 1971 to 2000 mean) despite the large 25-year precipitation event. Surface soil moisture conditions-reflecting an integrated response to precipitation, temperature, atmospheric humidity, and wind speed and which have direct effects on soil erodibility by wind (Ravi et al. 2006) - were significantly drier during much of the global-change-type year. Under the global-change-type conditions, annual rates of wind-driven horizontal sediment transport increased by 60\% relative to baseline conditions. Collectively, the results for both wind- and water-driven sediment transport revealed that during 


\section{Figure 2}

How do wet-dry climate extremes affect the wind-to-water transport ratio? (a) Wet climate extremes typically increase the amount of vegetation cover and thus reduce the amount of exposed surface soil to the erosive forces of wind and water (BSNE dust sampler in foreground); (b) dry climate extremes, in contrast, typically decrease the amount of protective vegetation cover and increase the potential for both wind and water erosion and transport (sediment check dam in background).

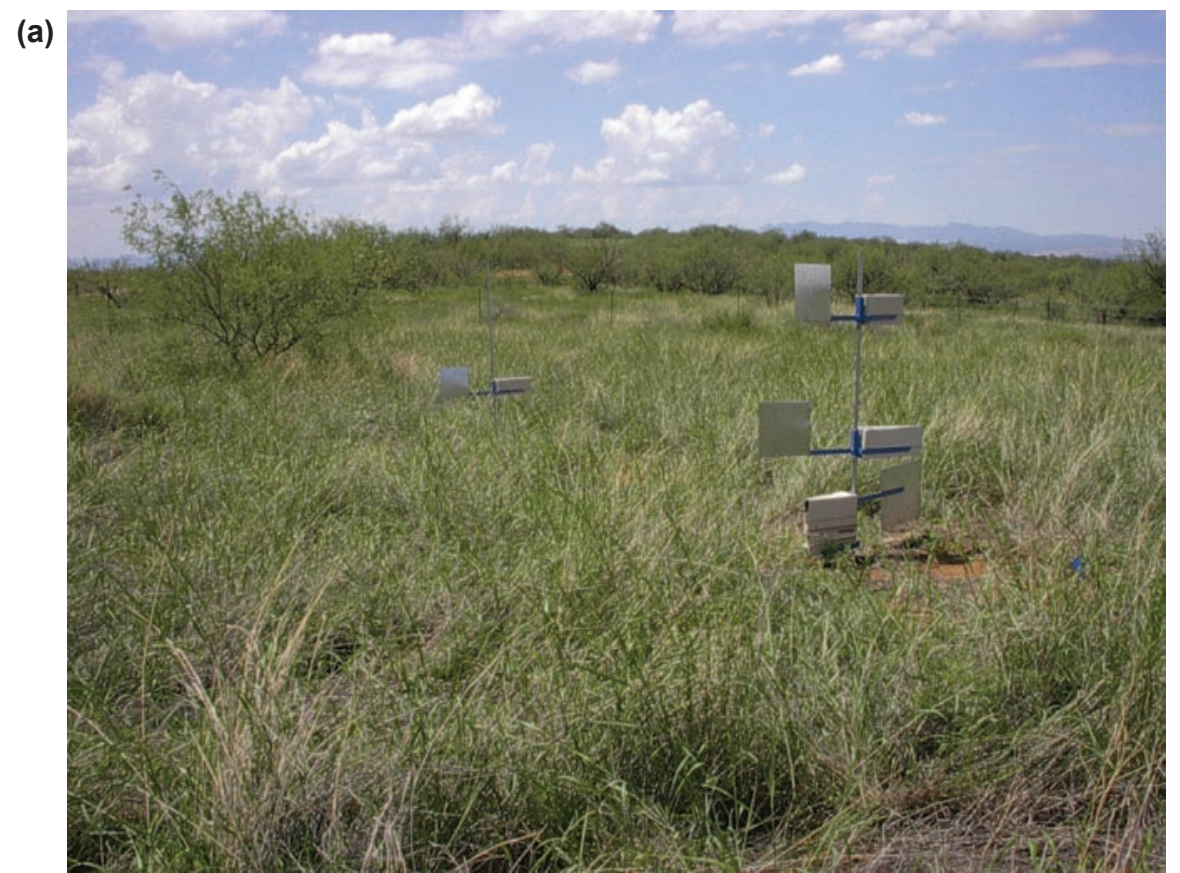

(b)

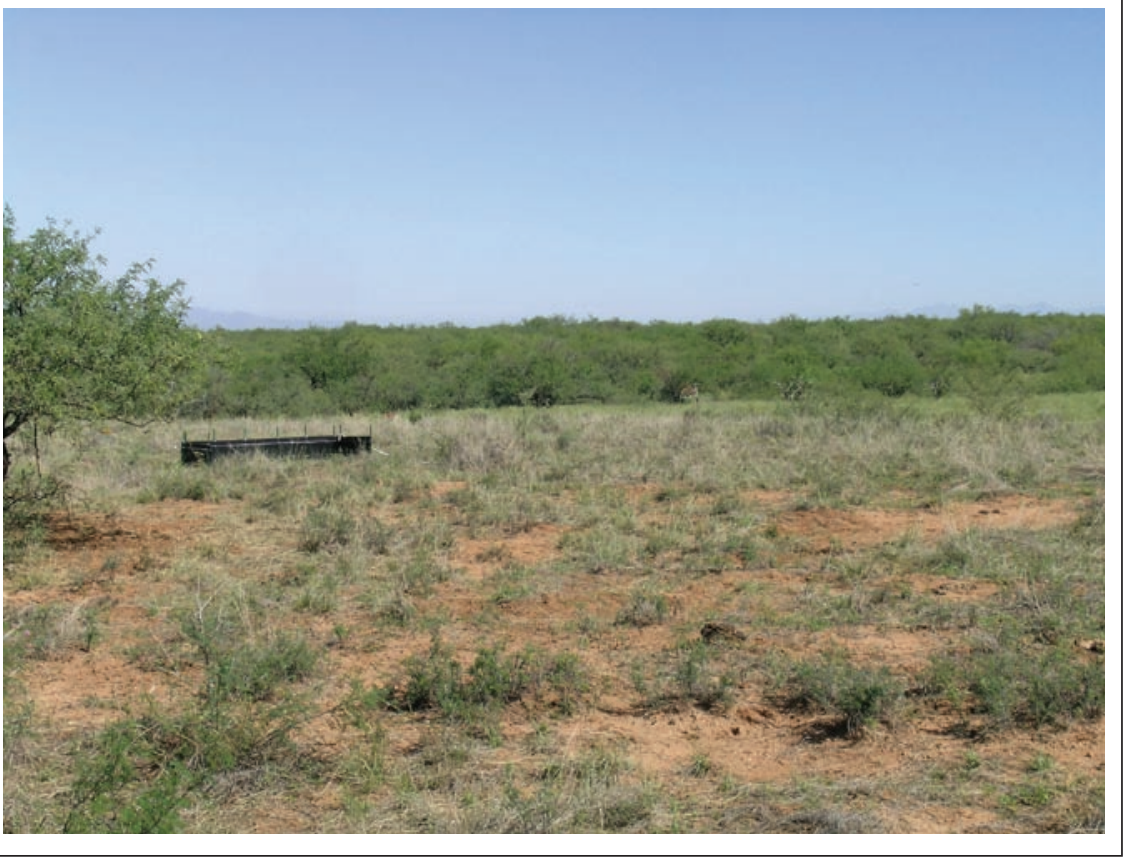

the global-change-type year, wind-driven sediment transport exceeded that of water by a factor of approximately 40 , representing more than an order-of-magnitude increase over the baseline year for which wind-driven sediment transport exceeded that of water by a factor of only approximately 3 (figure 3a). This jump in the relative rates of wind-to-water sediment transport is not necessarily intuitive given that the study period included the large 25 -year precipitation event (figure $3 b$ ).
The unusual wet-dry conditions associated with one year of the study provide a rare opportunity to consider how rates of wind- and water-driven sediment transport might vary with respect to each other not only under baseline conditions, but also under those that provide a rough proxy for a global-change-type extreme events. Note that under baseline conditions, as well as under global-change-type conditions, measureable amounts of winddriven sediment transport occurred over every one- to two-week sampling intervals throughout the duration of this study, highlighting that even though aeolian sediment transport is affected by periods with large dust events, it is a much more continuous process than fluvial sediment transport. These measurements provide more direct estimates of rates than modeled estimates, which are usually used for multiyear assessments. Of course, we should be cautious in over-generalizing from a single study at a single site, and several caveats should be considered. Under the time span of our study, the effects of variation in vegetation cover were minimized, but over longer time frames spanning multiple years with wet-dry extremes, the relative rates of wind- and water-driven sediment transport would likely be further altered due to climate-induced changes in vegetation. Notably, vegetation cover during this study, which was dominated by perennial grasses, was similar in both years and ranged between $60 \%$ and $80 \%$ in each year. In addition, because wind speed and vegetation cover were relatively constant between years, our results are likely relatively insensitive to the sequence of years (the year with wet-dry extremes preceded the baseline year). The ratio of wind- to water-driven sediment transport should vary substantially with a variety of site conditions besides climate, such as soil texture and slope (figure 1). In our case, we did not directly measure fluvial sediment transport in gullies and channels, and the soils at our site are sandy loam, both of which likely favor aeolian over fluvial processes. The site conditions that we focused on, however, are of general significance given the predominance of coarse texture soils in drylands and of uplands rather than gully or channel locations. 


\section{Figure 3}

(a) Cumulative wind- and water-driven sediment transport in a semiarid grassland for a period including a 25-year precipitation event (August) followed by the driest 9-month period (September to May) on the more than 100-year instrumental record; (b) wind-towater transport ratio for baseline conditions and global-change-type extreme events (reference totals indicated by arrows in [a]).

(a)

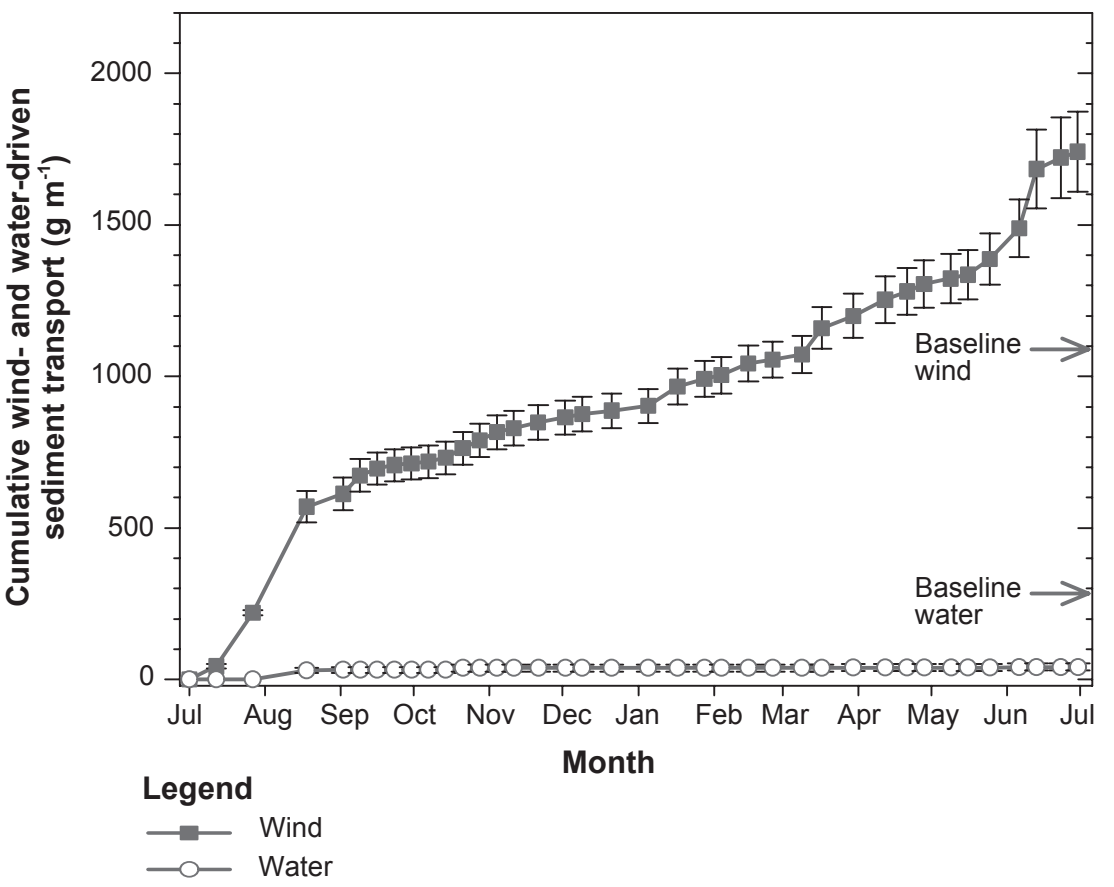

(b)

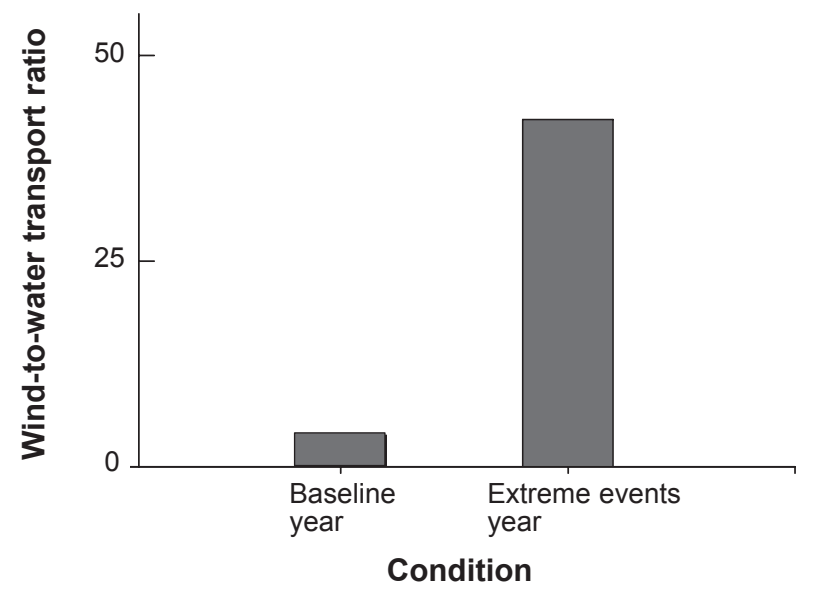

The more than an order-of-magnitude jump in wind-driven sediment transport over water-driven sediment transport that we document is reflective of local saltation and is of concern because enhanced rates of redistribution by aeolian processes from intercanopy to shrub patches often play an important role in driving desertification. In addition, because horizontal aeolian sediment fluxes are correlated with vertical fluxes reflecting erosion (Gillette et al. extreme events projected for many drylands (figure 4).

If this hypothesis is supported, such a change could trigger a substantial shift of land surface-atmosphere interactions for drylands. Further, an increase in atmospheric aerosols due to amplified dust emissions from dryland regions has the potential to exert widespread influence on global climate, even though uncertainty remains with respect to the direction and magnitude of change (IPCC 2007). Because wind-driven sediment transport is generally lower in grasslands than in other dryland ecosystems (Breshears et al. 2003; Breshears et al. 2009), such amplifications in dust emissions relative to water-driven sediment production may be even greater in other dryland ecosystems, particularly shrublands and highly degraded or barren sites.

This issue is of particular significance given that the southwestern United States is projected to transition, within years to decades, to a more arid climate comparable to that of the 1930s Dust Bowl (Seager et al. 2007), and many other dryland regions worldwide are also likely to experience increased aridity in the near future due to reduced precipitation and increased temperatures (IPCC 2007). Dust emissions are highly sensitive to changes in soil moisture and atmospheric humidity (Ravi et al. 2006), as well as the amount and distribution of protective vegetation cover at the soil surface (Gillette et al. 1996). Projected increases in drought frequency and severity for many drylands will likely increase soil susceptibility to wind erosion by drying out surface soil and resulting in a reduction in the amount of protective vegetation cover (IPCC 2007), both of which could further amplify dust emissions and land surface-atmosphere interactions over vast areas worldwide. Dust emissions from dryland areas could be further amplified due to projected increases in land-use intensity that are likely to occur in the future as a result of increasing human demand for ecosystem goods and services (MEA 2005). Because erosion depends on land management as well as climate, our results highlight the need for careful land management to avoid further amplification of dust emissions such as those that resulted 


\section{Figure 4}

Hypothetical sediment transport potential due to wind (yellow bars) and water (blue bars) under baseline conditions and global-change-type extreme events. Note that for baseline conditions, where the magnitudes of wind- and water-driven sediment transport are similar (left column), a transition to fewer but more extreme precipitation events (right column) could result in a substantial increase in the magnitude of winddriven sediment transport with respect to that of water. Transport is related to erosion, but large variations and uncertainties regarding the specifics of this relationship and how it varies with site conditions preclude directly comparing erosion based on transport.
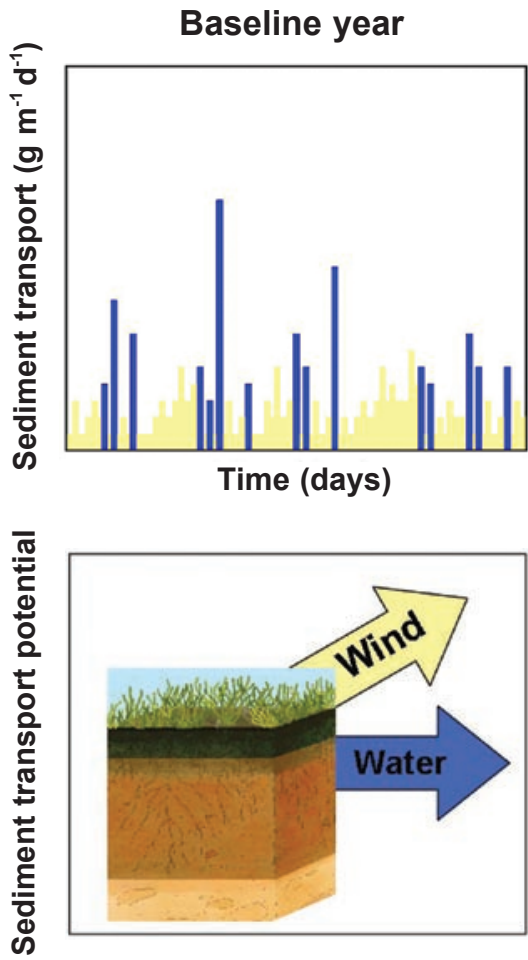

Baseline year

\section{Extreme events year}
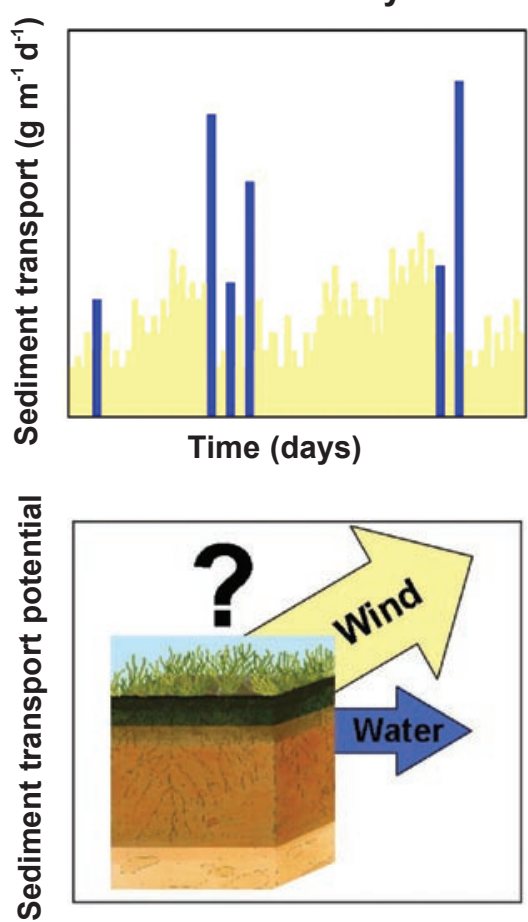

Extreme events year from post-1880 cattle grazing in the western United States (Neff et al. 2008).

More generally, wind- and waterdriven sediment transport processes are recognized as collectively influencing land surface dynamics (Aguiar and Sala 1999) but have most often been studied in isolation of one another (Field et al. 2009), or relative rates have only been inferred from soil pedology and biogeochemistry rather than by direct measurement. Direct measurements are particularly relevant for shorter time scales of months to years associated with land management. Sediment transport processes can have important ecological and environmental consequences and should be explicitly considered in the context of land management with respect to their relationship to soil erosion but more directly and per- haps equally importantly as indicators of soil surface dynamics. In short, we suggest that the wind-to-water transport ratio is a basic site characteristic relevant to soil conservation that should be more generally considered, as well as more frequently measured, and that it will be important to consider how this ratio changes under wet-dry extremes associated with contemporary climate change.

\section{ACKNOWLEDGEMENTS}

We thank Chris McDonald and Guy McPherson for setting up the experimental design and Travis Huxman, Darin Law, and Lisa Graumlich for comments. This study was supported by the Arizona Agricultural Experiment Station (DDB), the USDA Cooperative State Research, Education, and Extension Service (JPF, DDB; CSREES 2005-3842015809), the National Science Foundation (DDB,JPF;
NSF-DEB 0816162), and the Department of Energy (JJW; DE-AC52-06NA25396).

\section{REFERENCES}

Aguiar, M.R., and O.E. Sala. 1999. Patch structure, dynamics, and implications for the functioning of arid ecosystems. Trends in Ecology and Evolution 14:273-277.

Alfaro, S.C., and L. Gomes. 2001. Modeling mineral aerosol production by wind erosion: emission intensities and aerosol size distributions in source areas. Journal of Geophysical Research 106:18075-18084.

Breshears, D.D., J.J Whicker, M.P. Johansen, and J.E. Pinder III. 2003. Wind and water erosion and transport in semi-arid shrubland, grassland and forest ecosystems: Quantifying dominance of horizontal wind-drive transport. Earth Surface Processes and Landforms 28:1189-1209.

Breshears, D.D, J.J Whicker, C.B. Zou, J.P. Field, and C.D. Allen. 2009. A conceptual framework for dryland aeolian sediment transport along the grassland-forest continuum: effects of woody plant canopy cover and disturbance. Geomorphology 105:28-38.

Field, J. P., D.D. Breshears, C.B. Zou, and J.J. Whicker. 2011. How grazing and burning differentially alter wind and water erosion: Implications for rangelands. Ecological Applications 21(1):22-32. doi:10.1890/09-2369.1.

Field, J.P., D.D. Breshears, and J.J. Whicker. 2009. Toward a more holistic perspective of soil erosion: why aeolian research needs to explicitly consider fluvial processes and interactions. Aeolian Research 1:9-17.

Gillette, D.A. 1977. Fine particle emissions due to wind erosion. Transactions of the American Society of Agricultural Engineers 20:890-897.

Gillette, D.A., D.W. Fryrear, T.E. Gill, T. Ley, T.A. Cahill, and E.A. Gearhart. 1997. Relation of vertical flux of particles smaller than $10 \mu \mathrm{m}$ to aeolian horizontal mass flux at Owens Lake. Journal of Geophysical Research 102:26009-26015.

Gillette, D.A., G. Herbert, R.H. Stockton, and P.R. Owen. 1996. Causes of the fetch effect in wind erosion. Earth Surface Processes and Landforms 21:641-659.

Goudie, A.S., and N.J. Middleton. 2006. Desert dust in the global system. Heidelberg, Germany: Springer-Verlag.

IPCC (Intergovernmental Panel for Climate Change). 2007. Climate Change 2007:The Physical Science Basis, Contribution from Working Group 1 to the Third Assessment Report, Intergovernmental Panel for Climate Change. Cambridge, UK: Cambridge University Press. 
McClaran,M.P.,P.F.Ffolliott, and C.B.Edminster (tech. coords.). 2003. Santa Rita Experimental Range: 100 years (1903-2003) of Accomplishments and Contributions. Conference Proceedings., Tucson, Arizona, October 30-November 1, 2003. RMRS-P-30. Ogden, UT: US Department of Agriculture, Forest Service, Rocky Mountain Research Station http://www.fs.fed.us/rm/ pubs/rmrs_p030.html.

MEA (Millennium Ecosystem Assessment). 2005. Ecosystems and Human Well-being: Desertification Synthesis. Washington, DC:World Resources Institute.

Moss, A.J., and P.H. Walker. 1978. Particle transport by continental water flows in relation to erosion, deposition, soils, and human activities. Sedimentary Geology 20:81-139.

Neff, J.C., A.P. Ballantyne, G.L. Farmer, N.M. Mahowald, J.L. Conroy, C.C. Landry, J.T. Overpeck, T.H. Painter, C.R. Lawrence, and R.L. Reynolds. 2008. Increasing eolian dust deposition in the western United States linked to human activity. Nature - Geosciences doi:10.1038/ngeo133.
Oldeman, L., R. Hakkeling, and W. Sombroeck. 1990. World Map of the Status of Human-Induced Soil Degradation: An Explanatory Note. Wageningen, The Netherlands: International Soil Reference and Information Center; Nairobi, Kenya: United Nations Environment Programme.

Painter, T.H., A.P. Barrett, C.C Landry, J.C. Neff, M.P. Cassidy, C.R. Lawrence, K.E. McBride, and G.L. Farmer. 2007. Impact of disturbed desert soils on duration of mountain snowcover. Geophysical Research Letters 34:L12502, 10.1029/2007GL030208.

Pimentel, D., C. Harvey, P. Resosudarmo, K. Sinclair, D. Kurz, M. McNair, S. Crist, L. Shpritz, L. Fitton, R. Saffouri, and R. Blair. 1995. Environmental and economic costs of soil erosion and conservation benefits. Science 267:1117-1123.

Ravi, S., P. D’Odorico, B. Herbert, T. Zobeck, and T.M. Over. 2006. Enhancement of wind erosion by fire-induced water repellency.Water Resources Research 42:W11422.

Rosenfeld, D.,Y. Rudich, and R. Lahav. 2001. Desert dust suppressing precipitation: desertification feedback loop. Proceedings of the National Academy of Science USA 98:5975-5980.

Seager, R., M.F. Ting, I. Held, Y. Kushnir, J. Lu, G. Vecchi, H.P. Huang, N. Harnik, A. Leetmaa, N.C., Lau, C.H. Li, J.Velez, and N. Naik. 2007. Model projections of an imminent transition to a more arid climate in southwestern North America. Science 316:1181-84.

Shao, Y., M.R. Raupach, and J.F. Leys. 1996. A model for predicting aeolian sand drift and dust entrainment on scales from paddock to region. Australian Journal of Soil Research 34:309-342.

Sweet, M.L. 1999. Interaction between aeolian, fluvial, and playa environments in the Permian Upper Rotliegend Group, UK southern North Sea. Sedimentology 46:171-187.

Toy, T.J., G.R., Foster, and K.G. Renard. 2002. Soil erosion: Processes, prediction, measurement and control. New York: John Wiley and Sons.

Trimble, S.W., and P. Crosson. 2000. U.S. Soil erosion rates-myth and reality. Science 289:248-250. 